\title{
STRESS, ROLES AND RESPONSIBILITIES OF SINGLE MOTHERS IN MALAYSIA
}

\author{
Intan Hashimah Mohd Hashim \\ Women Research and Development Centre/School of Social Sciences \\ Universiti Sains Malaysia, \\ Penang, Malaysia \\ Azman Azwan Azmawati \\ Women Research and Development Centre/School of Communication \\ Universiti Sains Malaysia, \\ Penang, Malaysia \\ Noraida Endut \\ Women Research and Development Centre \\ Universiti Sains Malaysia, \\ Penang, Malaysia
}

\section{ABSTRACT}

Life as a single mother is often associated with great demands and many challenges. This study examines how a group of single mothers in Malaysia views sources of stress and challenges in their lives. It also investigates perceived roles and responsibilities of single mothers. Three hundred single mothers from all over Malaysia were interviewed in this study. Single mothers reported relatively low level of stress that was mostly related to financial (insufficient pay) and day-to-day living. They had fairly low stress on issues related to romantic partner and romantic relationships. They however reported extensive roles and responsibilities. Single mothers reported feeling responsible across various domains of life including for their own health and well-being and also for the health and wellbeing of their family and friends. They reported high level of coping and particularly oriented towards solving the problems. They also reported general satisfaction over life. Correlation analysis indicated significant positive relationships between roles and responsibilities and life satisfaction and coping in which coping was associated with higher level of roles and responsibilities and life satisfaction. There was also a negative correlation between stress and life satisfaction in which more stress was associated with lower life satisfaction. Findings indicated a substantial nurturing role of single mothers and provided important policy and practice implications that highlights the important to study and continuously improve quality of life for these women. Finally, this study highlights the important to continuously study and support, important but marginalized groups in society such as single mothers.

Keywords: Stress, roles, single mothers, Malaysia

\section{INTRODUCTION}

Life as a single mother is often associated with great demands and many challenges. Single mothers are more likely to report higher level of chronic stress and episodes of depression compared to married mothers (Cairney, Boyle, Offord \& Racine (2003). What are the sources of stress for single mothers? First and foremost, single mothers with children represent the most impoverished families in the country 
compared to those with two parents. Lone mothers with dependent children are the poorest of all demographic groups (Olson \& Banyard, 1993). These single bread winners are more likely to have jobs with poor pay and yet they are responsible for more people including themselves and their children. Financial represents one of the major sources of stress for single mothers.

In their study on the sources of daily stress among single mothers with young children, Olson and Banyard (1993) examined other sources of stress and identified interactions with children and parental stress as another major source of stress. In that study, single mothers reported incidents of children's misbehavior as particularly distressful (Olson \& Banyard, 1993). In addition, social interactions with other adults also represent another source of stress for these women (Olson \& Banyard, 1993). This study examines how a group of single mothers in Malaysia view sources of stress and challenges in their lives. From previous studies, stress for single mothers is likely to come from various sources including financial and relationships.

Related to sources of stress are the roles and responsibilities held by single mothers. Roles and responsibilities in themselves are not necessarily stressful. However, overwhelming roles and responsibilities across many different areas can be a source of stress. For example, a single mother who is responsible for the health and well-being of herself, children and other family members are likely to be overwhelmed and experienced a higher level of stress compared to women with lesser roles and responsibilities. In a study comparing the housework between working married women and their husbands, women who work outside the home spend as much as three hours more on doing housework compared to their husbands (Berardo, Shenan and Leslie, 1987). The patterns are likely to be magnified when the women are actually single mothers and the household tasks are not shared with a partner. This study investigates perceived roles and responsibilities of single mothers in Malaysia in order to understand the full range of roles carried by these women.

Studies have shown single mothers to cope relatively well in manners that are active and self-reliant (Olson \& Banyard, 1993). This study investigates how single mothers cope with their lives in Malaysia. A classic work on coping defined it as the cognitive and behavioral efforts to control, lessen or tolerate internal and/or external demands produced by a stressful experience (Lazarus \& Folkman, 1984). In general, coping has two basic functions, one is to manage emotion or distress i.e. emotion-focused coping and the other is to deal with the problem that is causing the distress i.e. problem-focused coping. This study explores which are more likely to be employed by single mothers.

Several studies have looked at life satisfaction among single mothers (Choy \& Moneta, 2002; Wan, Jaccard \& Ramey; 1996). In their study that compared the life satisfaction of single mothers, married mothers and married fathers, Wan et al (1996) found social support from sources outside family to be an important predictor of life satisfaction among single mothers. In another study, self-acceptance is found to be an important predictor of life satisfaction among 49 single mothers in Hong Kong (Choy \& Moneta). In this study, life satisfaction among single mothers is examined. This study also examines how sources of stress, roles and responsibilities, and coping can be related to life satisfaction.

\section{THIS STUDY}


The aim of this study is to understand the stress, role and responsibilities, coping strategies and life satisfaction among single mothers in Malaysia. It also investigates the relationship between these 4 variables.

\section{METHODOLOGY}

\section{Participant and procedure}

Three hundred single mothers between the ages of 18-66 participated in this study. Mean of age of the participants was 49.81 (SD 9.19). The study was conducted in Malaysia. A majority of the participants were Malays (70.3 \%) but other ethnic groups were also represented $(7.0 \%$ Chinese, $20.0 \%$ Indians and $2.7 \%$ others). Mean of income was RM1106.40 (SD=951.77).

Respondents were identified via personal contact or using a systematic snowballing technique. In the systematic snowballing technique, advertisements were placed around a public university for recruitment of enumerators. As a result, twenty-six university students were recruited as enumerators and they were requested to identify potential respondents. The criteria for respondents were Malaysian women between the ages of 18 and 66 and these women must have been married before. Upon agreement, these women were interviewed at a time and place convenient for them.

\section{Interview schedule}

The semi-structured interview consisted of 16 different sections but for the purpose of this paper, the focus is only on the background information, stress and problems associated with life (22 items), roles and responsibilities (18 items), coping strategies (6 items) and life satisfaction (5 items).

\section{Background Information}

This section assesses the background including age, ethnicity and income.

\section{Stress}

In this sections, respondents were asked to rate their level of stress according to the scales given - not affected at all, rarely affected, sometimes affected, mostly affected, affected all the time - across 22 items that include parental care, child care, domestic duties, debts and pay. Cronbach's a for this scale in this sample is 0.89 .

\section{Roles and responsibilities}

In this section, respondents were asked to rate their whether they are responsible for the following items. Altogether there are 18 items that include health care and well-being of self, family, parents and friends. Cronbach's a for this scale in this sample is 0.91 .

\section{Coping}

Respondents were asked to report the kind of coping strategies they frequently used. Six items were divided into problem focused (2) and emotion-focused (4 items). Example of problem-focused is "When 
facing problems, I often seeks solutions" and Example of emotion-focused item is "When facing problems, I try to make myself feel better". Cronbach's a for this scale in this sample is 0.70 .

Life satisfaction

Respondents were asked to report their life satisfaction across 5 items. These items include satisfaction across own life and relationships. Cronbach's a for this scale in this sample is 0.87

\section{RESULTS}

Table 1: $M$ and SD Stress

\begin{tabular}{llcc}
\hline & Item & $\mathrm{M}$ & $\mathrm{SD}$ \\
\hline 1 & Parental care & 1.5920 & .94162 \\
2 & Child care & 2.2967 & 1.09818 \\
3 & Domestic duty & 2.3000 & 1.06793 \\
4 & Relationship with bosses at work & 1.6600 & .96998 \\
5 & Relationship with colleagues at work & 1.6567 & .98761 \\
6 & Work load & 1.9867 & 1.04409 \\
7 & Promotional issue & 1.5200 & .97610 \\
8 & Current marital status & 1.4467 & .91466 \\
9 & Relationship with current partner & 1.2067 & .63664 \\
10 & Relationship with previous partner & 1.5570 & .99752 \\
11 & Inadequate pay & 2.7167 & 1.30719 \\
12 & Debt & 2.3712 & 1.22583 \\
13 & Accumulation of wealth & 2.2876 & 1.17762 \\
14 & Traffic jam & 1.9766 & 1.11854 \\
15 & Daily chores & 2.2900 & 1.05971 \\
16 & Communicating with others & 1.8633 & .94213 \\
17 & Current health & 2.3433 & 1.03716 \\
18 & Future health & 2.4600 & 1.08889 \\
19 & Sources of health care & 2.2833 & 1.05519 \\
20 & Governmental financial policy & 2.0333 & 1.13277 \\
21 & Law & 1.4967 & .87131 \\
22 & Support from formal institutions & 1.6167 & .95539 \\
23 & Total & 1.9552 & .58440 \\
\hline
\end{tabular}

From Table 1, stress was generally low for single mothers with mean of total score of less than 2.00 . Stress however was mainly related to financial aspect (e.g. inadequate pay, debts and accumulation of wealth, governmental financial policy). Daily chores, child care and domestic duty represent another category of sources of stress that is more related to day-to-day functioning of a single mother. Finally health is also another source of stress and these include current, future and sources of health care. Romantic relationship with current and future partner represents the least important source of stress. 
Table 2: M and SD Roles and responsibilities

\begin{tabular}{llcc}
\hline & Item & $\mathrm{M}$ & $\mathrm{SD}$ \\
\hline 1 & Personal health care & 3.7365 & .98367 \\
2 & Personal well-being & 3.7128 & .96127 \\
3 & Pet care & 2.6544 & 1.30964 \\
4 & Wealth care & 3.6455 & 1.03370 \\
5 & Parental health care & 3.2373 & 1.33426 \\
6 & Parental well-being & 3.1791 & 1.33722 \\
7 & Financial support for parents & 2.9155 & 1.26342 \\
8 & Tangible support for parents & 3.0610 & 1.27895 \\
9 & Emotional support for parents & 3.0644 & 1.25055 \\
10 & Family health care & 3.7282 & .92293 \\
11 & Family well-being & 3.7047 & .95349 \\
12 & Financial support for family & 3.4866 & 1.09859 \\
13 & Tangible support for family & 3.5503 & 1.00796 \\
14 & Emotional support for family & 3.5117 & .95311 \\
15 & Friend's well-being & 2.8027 & 1.02871 \\
16 & Financial support for friends & 2.1611 & 1.05132 \\
17 & Tangible support for friends & 2.6154 & .94969 \\
18 & Emotional support for friends & 2.7391 & .95828 \\
19 & Total & 3.1995 & .68093 \\
\hline
\end{tabular}

From Table 2, the analysis suggests that single mothers were mainly responsible for the health and well-being of themselves and their immediate family. They were somewhat responsible for parents but least responsible for friends. Generally, they still indicate a high level of nurturing roles across a broad range of things and people around them.

Table 3: M and SD Coping

\begin{tabular}{llcc}
\hline & Item & $\mathrm{M}$ & SD \\
\hline 1 & Emotional sharing with families and close friends & 3.3800 & .93372 \\
2 & Self-calming & 3.4600 & .95118 \\
3 & Seeking solutions & 3.6600 & .92045 \\
4 & Seeking support from families and close friends & 3.2033 & .96874 \\
5 & Refocussing on other things & 2.7967 & 1.05469 \\
6 & Engaging in other activities with families and close friends & 2.7167 & 1.14634 \\
7 & Total & 3.2028 & .62976 \\
\hline
\end{tabular}

From Table 3, it can be concluded that single mothers generally have a high level of coping. They also were more likely to engage in problem-focused coping. Distractions were not as widely used as direct focusing on the problems. 
Table 4: M and SD Life Satisfaction

\begin{tabular}{llcc}
\hline & Item & $M$ & SD \\
\hline 1 & Happy with life & 3.2033 & .98245 \\
2 & Happy with what I am doing & 3.2733 & .93535 \\
3 & Happy with relationships & 3.4108 & .92977 \\
4 & Satisfied with accomplishment & 3.0767 & 1.02026 \\
5 & Not change anything & 2.6467 & 1.20277 \\
6 & Total & 3.1205 & .82225 \\
\hline
\end{tabular}

From Table 4, single mothers reported high satisfaction with life. They reported especially high satisfaction with relationships but also indicated the intention to continuously improving things in their life.

Table 5 Correlations between coping, stress, role and responsibilities and life satisfaction.

\begin{tabular}{|c|c|c|c|c|c|}
\hline & & Stress & $\begin{array}{c}\text { Roles and } \\
\text { responsibilities }\end{array}$ & Coping & Life satisfaction \\
\hline \multirow[t]{3}{*}{ Stress } & Pearson Correlation & & -.044 & .061 & $-.365^{\star *}$ \\
\hline & Sig. (2-tailed) & & .459 & .290 & .000 \\
\hline & $\mathrm{N}$ & & 284 & 298 & 295 \\
\hline \multirow{3}{*}{$\begin{array}{c}\text { Roles and } \\
\text { responsibilities }\end{array}$} & Pearson Correlation & & & $.187^{* *}$ & $.372^{* *}$ \\
\hline & Sig. (2-tailed) & & & .001 & .000 \\
\hline & $\mathrm{N}$ & & & 286 & 255 \\
\hline \multirow[t]{3}{*}{ Coping } & Pearson Correlation & & & & $.223^{* \star}$ \\
\hline & Sig. (2-tailed) & & & & .000 \\
\hline & $\mathrm{N}$ & & & & 297 \\
\hline
\end{tabular}

${ }^{* *}$. Correlation is significant at the 0.01 level (2-tailed).

From Table 5, there were significant positive relationships between roles and responsiblities and coping in which coping was higher when roles and responsibilities was high. There was also a negative correlation between stress and life satisfaction in which more stress was associated with lower life satisfaction. Coping however, led to more life satisfaction.

\section{DISCUSSION AND CONCLUSION}

Single mothers in this study reported relatively low level of stress but the one that was mostly related to financial (insufficient pay), day-to-day living and health concern. They had fairly low stress on issues related to romantic partner and romantic relationships. This is consistent with previous studies that found financial to be a major source of stress. This finding also highlights the areas in which single 
mothers needs most help. These areas are financial, day-to-day living and health. Formal or informal supports tailored to address these sources of stress can improve the quality of life for single mothers tremendously. Single mothers also reported extensive roles and responsibilities. Single mothers reported feeling responsible across various domains of life including for their own health and well-being and also for the health and wellbeing of their family and friends. This finding indicates a substantial nurturing role played by single mothers and highlights the importance of policy and practice implications to improve the quality for these women. By ensuring a good quality of life for women can help improve the quality of life of other people under their care. Single mothers reported high level of coping that is particularly oriented towards solving the problems. They also reported general satisfaction over life. These two are good news. Finally, this study highlights the important to continuously study and support, important but marginalized groups in society such as single mothers.

\section{REFERENCES}

Berardo, D.H, Shena, C.L. \& Leslie, G.R. (1987). A residue of tradition: jobs, careers, and spouse's time in housework. Journal of Marriage and Family, 49, 381-390.

Brescoll, V.L. \& Uhlmann, E.L. (2005). Attitudes towards traditional and nontraditional parents. Psychology of Women Quarterly, 29 (4), 436-445.

Cairney, J, Boyle, M., Offord, D.R. \& Racine, Y. (2003) Stress, social support and depression in single and married mothers. Social Psychiatry Psychiatric Epidemiology 38, 442-449.

Cohen, S. \& Wills, T.A. (1985). Stress, social support and the buffering hypothesis. Psychological Bulletin. Vol. 98, 310-357.

Choy, W.C.W. \& Moneta, G.B.. (2002) The interplay of autonomy and relatedness in Hong Kong chinese single mothers. Psychology of Women Quarterly. 26,186-199.

Lazarus, R.S., \& Folkman, S. (1984). Stress, Appraisal and Coping. New York:Springer.

Leslie, L.A \& Anderson, E.A (1988). Men's and women's participation in domestic roles: Impact on quality of life and marital adjustment. Journal of Family Psychology, 2(2), 212-226.

Luo, L. (1994). Life events, social support and depression amongst Taiwanese housewives. Counselling Psychology Quarterly. 7 (2), 221-226.

McBride, A.B. (1990). Mental health effects on women's multiple roles. American Psychologist, 45 (3), 381-384.

Nathawat, S.S. \& Mathur, A (1992). Marital adjustment and subjective well-being in Indian-educated housewives and working women. The Journal of Pscyhology, 127 (3), 353-358.

Olson, S.L. \& Banyard, V. (1993) Stop the world so I can get off for a while; sources of daily stress in the lives of low-income single mothers of young children. Family relations. 42. 50-56. 
Pare, E. (2008). Locating mothers: how cultural debates about stay-at-home versus working mothers define women and home. Journal of Family Issues, 29(4), 437-464.

Wan, C.K., Jaccard, J, \& Ramey, S (1996). The relationship between social support and life satisfaction as a function of family structure. Journal of Marriage and Family. 58. 502-513.

\section{ACKNOWLEDGEMENT}

This study is made possible by the Research University's (RU) grant from Universiti Sains Malaysia 